Original Research Article

\title{
Practice of self-medication among medical students in a region of northern state of India
}

\author{
Sunita Singh ${ }^{1 *}$, Ranjana Singh ${ }^{2}$, Vivek Singh ${ }^{3}$, Barakha Gupta $^{4}$
}

${ }^{1}$ Department of Pharmacology, North DMC Medical College \& Hindu Rao Hospital, New Delhi, India

${ }^{2}$ Department of Community

Medicine, ${ }^{3}$ Department of

Pharmacology, ${ }^{4}$ Department of

Forensic Medicine, Saraswathi

Institute of Medical Sciences,

Hapur, Uttar Pradesh, India

Received: 05 December 2018

Revised: 02 February 2019

Accepted: 07 February 2019

\section{*Correspondence to:}

Dr. Sunita Singh,

Email: drsunitakr@gmail.com

Copyright: (C) the author(s), publisher and licensee Medip Academy. This is an openaccess article distributed under the terms of the Creative Commons Attribution NonCommercial License, which permits unrestricted noncommercial use, distribution, and reproduction in any medium, provided the original work is properly cited.

\begin{abstract}
Background: Self-medication usually leads to irrational drug utilization pattern leading to various issues like economic burden, incomplete treatment and antibiotic resistance. Self-medication is a common practice in developing countries and prevalent among medical students, influencing their future decision making as medical professional. The current study was carried out to determine the prevalence of self-medication among medical students and their attitude towards the same.
\end{abstract}

Methods: A cross-sectional questionnaire based study was conducted in a tertiary care teaching hospital from July 2015 to Oct 2015. Structured and validated questions were used to collect information about knowledge, attitude and practice of self-medication among undergraduate medical students. The study included total of 328 participants. Data were collected from each participant and analyzed statistically by using SPSS version 20 for count and percentages.

Results: A total of 328 subjects studying at a medical school were assessed regarding their practice, attitude and perception of self-medication behavior. Out of total recruited subjects, $53 \%$ were males and $47 \%$ were females. The prevalence of self-medication among recruited subjects was $89.9 \%$. Symptoms like fever, Headache and weakness were the most common reasons of selfmedication. The most commonly used drugs were antipyretic, analgesics $(81.7 \%)$, antibiotics $(51.2 \%)$. Approximately $15 \%$ subjects were not aware about the completion of the course of antibiotic treatment. Subjects obtained information and procured drugs from their family members, friends and pharmacist and the reasons for this were cited as lack of time, minor ailments and quick relief. Only $32.6 \%$ students opined that self-medication should be encouraged in future.

Conclusions: Current study reveals that practice of self-medication is highly prevalent among medical students without adequate knowledge of drugs used. Students should be educated regarding advantages and disadvantages of selfmedication.

Keywords: Awareness, Attitude, Medical students, Self-medication

\section{INTRODUCTION}

Acquisition of medicines without prescription, use of old prescriptions to procure medicines from chemists and using medication that is being used by friend, relatives, or other members of the society without consulting the medical practitioner is known as self-medication. ${ }^{1}$ As per the World Health Organization (WHO), self-medication is the selection and use of medicines by individuals to treat self-recognized illness or symptoms. ${ }^{2}$ The International Pharmaceutical Federation (IPF) defines self-medication as the use of non-prescription medicines by on their own initiative. $^{3}$

In developing country access to a medical doctor for every patient is not yet achieved. Treatment without prescription is very common. Self-medication is an important health concern in India. ${ }^{4,5}$ To some extent, self-medication may 
be a helpful strategy in reducing the patient load on doctors in developing country like India for the treatment of general ailments not necessarily requiring medical consultation. Appropriate and authentic self-medication can be the cheaper alternative for treating common illnesses as pointed out by the WHO. ${ }^{2}$ This may possibly minimize the irrational use of drugs.

On the other side, self-medication may lead to complications like delay in the diagnosis of the disease, harmful drug interactions and antibiotic resistance due to incomplete course and wrong selection of antibiotic. This has been proved by various studies. Hence, such practices if not checked will probably increase economic burden on the healthcare system of our country. 8,9 Further, antimicrobial resistance and dependence is a common problem worldwide, particularly in the developing countries where antibiotics are often available without prescription.

Use of self-medication is commonly seen in developing countries and also prevalent among medical students influencing their decision making as a medical professional in future. As medical students will be future practitioners, the issue of self-medication among these students require special attention. There is limited literature on the prevalence of self-medication among medical students and their attitude towards the same. The present study was conducted to assess the prevalence, attitude and perception about the practice of selfmedication among under graduate medical students of a Medical School in the western part of the state of Uttar Pradesh in Northern India.

\section{METHODS}

This was a cross-sectional questionnaire based study conducted at Saraswathi Institute of Medical Sciences (SIMS), Hapur, a tertiary care teaching hospital in the Northern state of Uttar Pradesh in India. The approval of the Institutional ethical committee (IEC) was obtained. A total of 328 subjects were recruited between July 2015 to Oct 2015. Inclusion criteria were 1) undergraduate medical student 2) consent to participate in the study. Those subjects who did not fulfill the exclusion criteria were excluded. Structured and validated questionnaire was used for collecting the necessary information about the knowledge, attitude and practice of self-medication. Enrolled participants were explained about the nature and purpose of the study. After taking informed consent, Questionnaires were distributed among the participants. Collected data were entered into case report forms and later into excel spreadsheet. For statistical analysis, Chisquare test was used to find out relationship between the variables. All Statistical analysis for frequency and percentages was done using SPSS version 20 software.

The study was carried out to determine prevalence of selfmedication among medical students and their attitude towards the same.

\section{RESULTS}

A total of 328 subjects, aged between 18-27years participated in the present study.

Maximum participants (58.2\%) were from the age group 17-20 years followed by $40.3 \%$ in the age group of $21-24$ year. Out of all participants, $174(53 \%)$ were males and $154(47 \%)$ were females. An insignificant association is observed between age group and sex of the studied participants (Table 1).

\section{Table 1: Distribution of subjects according to age group and sex.}

\begin{tabular}{|lll|l|}
\hline $\begin{array}{l}\text { Age-group } \\
\text { (Years) }\end{array}$ & $\begin{array}{l}\text { Female } \\
\text { n }(\%)\end{array}$ & $\begin{array}{l}\text { Male } \\
\text { n }(\%)\end{array}$ & $\begin{array}{l}\text { Total } \\
\text { n }(\%)\end{array}$ \\
\hline $17-20$ & $86(45)$ & $105(55)$ & $191(58.2)$ \\
\hline $21-24$ & $66(50)$ & $66(50)$ & $132(40.3)$ \\
\hline $25-28$ & $2(40)$ & $3(60)$ & $05(1.5)$ \\
\hline Total & $154(47.0)$ & $174(53.0)$ & $328(100)$ \\
\hline
\end{tabular}

Chi- square-1.665, df-2, $\mathrm{p}=0.435$

Table 2: Practice of self-medication among recruited subjects.

\begin{tabular}{|lll|}
\hline Self-medication & $(\mathbf{n})$ & $(\%)$ \\
\hline Yes & 295 & 89.9 \\
\hline No & 33 & 10.1 \\
\hline Total & 328 & 100.0 \\
\hline
\end{tabular}

Table 2 shows that out of total (328) participants 295 $(89.9 \%)$ practiced self-medication.

Table 3: Indications for self-medication.

\begin{tabular}{|lll|}
\hline Indications for self-medication & $(\mathbf{N})$ & $(\%)$ \\
\hline Fever, headache, weakness & 247 & 75.3 \\
\hline Cough and cold & 169 & 51.5 \\
\hline Acidity, nausea and vomiting & 100 & 30.5 \\
\hline Diarrhoea & 59 & 17.98 \\
\hline Skin & 40 & 12.2 \\
\hline Eye and ear problem & 26 & 7.9 \\
\hline $\begin{array}{l}\text { Sleeplessness, anxiety/bad } \\
\text { mood/tension }\end{array}$ & 20 & 6.1 \\
\hline Pain abdomen and dysmenorrhea & 32 & 9.8 \\
\hline Intense desire to take drug & 8 & 2.4 \\
\hline
\end{tabular}

The most common indication for self-medication was fever, headache and weakness in 247 (75.3\%) of the subjects followed by cough and cold in $169(51.5 \%)$ subjects. Other conditions were acidity, nausea and vomiting reported in $100(30.5 \%)$, diarrhea in 59 $(17.98 \%)$, skin diseases in $40(12.2 \%)$, pain abdomen, dysmenorrhoea in 32 (9.8\%), eye and ear problem in 26 $(7.9 \%)$, sleeplessness, anxiety/bad mood and tension in 20 $(6.1 \%)$. Some of the subjects $8(2.4 \%)$ were taking drugs for intense desire to take drug (Table 3 ). 
Table 4: Distribution of participants according to commonly used drugs for self-medication.

\begin{tabular}{|lll|}
\hline Drugs used for self-Medications & N & $(\%)$ \\
\hline Antipyretics, analgesics & 268 & 81.7 \\
\hline Antibiotics & 168 & 51.2 \\
\hline Eye/ear drop, topical ointment & 123 & 37.5 \\
\hline Anti-allergic drugs & 84 & 25.6 \\
\hline Antacids, antiemetics & 81 & 24.7 \\
\hline Tonics & 34 & 10.4 \\
\hline Did not remember & 22 & 6.7 \\
\hline Antidepressants, antianxiety, sedatives & 21 & 6.4 \\
\hline
\end{tabular}

Antipyretics, analgesics in $268(81.7 \%)$ and antibiotics in 168 (51.27) were the commonly used drugs. Other used drugs were eye/ear drops, topical ointments in123 (37.5\%), anti-allergic drugs in 84 (25.6\%), and antacids and antiemetic in $81(24.7 \%)$ subjects. Some subjects 21 $(6.4 \%)$ were also taking antidepressants, antianxiety and sedative drugs. 22 subjects $(6.7 \%)$ did not remember the name of the drugs (Table 4).

Table 5: Distribution of drugs according to their source of procurement.

\begin{tabular}{|lll|}
\hline Sources of drug information & n & $(\%)$ \\
\hline Family members and friends & 280 & 85.4 \\
\hline Pharmacist & 183 & 55.8 \\
\hline Books, magazines, media & 112 & 34.1 \\
\hline Previous prescriptions & 30 & 9.1 \\
\hline
\end{tabular}

Family members and friends in 280 (85.4\%) and Pharmacist in $183(55.8 \%)$ were the main sources of drug information and procurement. 112 students (34.1\%) students got information through books/magazines and media followed by use of previous prescriptions by 30 $(9.1 \%)$ (Table 5).

Table 6: Reasons for self-medication.

\begin{tabular}{|lll|}
\hline Reasons & n & $(\%)$ \\
\hline Time saving /lack of time & 107 & 32.6 \\
\hline Minor ailment illness too trivial & 159 & 48.5 \\
\hline Urgency/quick relief & 141 & 43.0 \\
\hline $\begin{array}{l}\text { Confidence in self-diagnosis previous } \\
\text { expertise / old prescription }\end{array}$ & 92 & 28.0 \\
\hline
\end{tabular}

*MR Table

Minor illness and lack of time are the most common reasons for self-medication in 107 (32.6\%) of recruited subjects. Other reasons for self-medication include urgency, quick relief, cost effectiveness, confidence in self-diagnosis and pharmacological knowledge, previous expertise and old prescriptions (Table 6).

The most common preferred route for administration of medicine is oral route $319(97.3 \%)$, followed by injection 23(7.0\%), and inhalational $16(4.9 \%)$ (Table 7).
Table 7: Route of administration.

\begin{tabular}{|lll|}
\hline Route of administration & n & $(\boldsymbol{\%})$ \\
\hline Oral & 319 & 97.3 \\
\hline Injection & 23 & 7.0 \\
\hline Inhalation & 16 & 4.9 \\
\hline
\end{tabular}

Regarding awareness of completing the course of antibiotics, total of 278 subjects $(84.8 \%)$ were aware of this and some subjects $49(14.9 \%)$ were not completing the course of antibiotics. Most of the subjects 288 (87.8\%) checked the expiry date of the drugs before taking the drug and $40(12.2 \%)$ of the subjects were not checking the expiry date of the drug before use (Table 8).

Table 8: Distribution according to the awareness of various aspects of self- medication.

\begin{tabular}{|lll|}
\hline $\begin{array}{l}\text { Awareness of various aspects of } \\
\text { Self-medication }\end{array}$ & No. & Percent \\
\hline $\begin{array}{l}\text { Importance of completing course of } \\
\text { medicine }\end{array}$ & 288 & 87.8 \\
\hline Expiry date & 278 & 84.8 \\
\hline
\end{tabular}

It was observed that 98 subjects $(32.6 \%)$ were in favor of self-medication in future.158 subjects (48.2\%) were without any comment on future use of self-medication, 41 students $(12.5 \%)$ disagreed for self-medication and 21 $(6.4 \%)$ subjects said that they will advise others to take self-medication (Table 9).

Table 9: Attitude of participants towards self-medication.

\begin{tabular}{|lll|}
\hline Attitude & $\mathbf{n}$ & $(\boldsymbol{\%})$ \\
\hline No comments & 158 & 48.2 \\
\hline Agreed to use self-medication in future & 98 & 32.6 \\
\hline Disagree & 41 & 12.5 \\
\hline Advise others to take self-medication & 21 & 6.4 \\
\hline Total & 328 & 100.0 \\
\hline
\end{tabular}

\section{DISCUSSION}

We conducted the current study to evaluate the practices, attitude and perception of self-medication among medical students. A total of 328 subjects were recruited. Of all recruited subjects, $174(53.4 \%)$ were males and 154 $(46.6 \%)$ were females and aged between $18-26$ years. The self-medication is widely practiced $(89.9 \%)$ by the undergraduate medical students of single medical institute. These practices of self-medication among medical students may have grave consequences as it may influence their future professional decision.

A study in Karachi reported the prevalence of selfmedication to be $76 \% .{ }^{10}$ In other studies conducted within India, the prevalence of self-medication among the medical students was shown to be ranging between $57.1 \%$ and $92 \% .{ }^{11-13}$ This could be attributed to the apron, which signifies the professional look and thus facilitates easy 
purchase of drugs without prescription in developing countries. Unlike in some of the developed countries where stringent rules are applied to dispense the drugs, in many developing nations including India it is easier to procure drugs off the counter.

This survey showed a higher prevalence rate of selfmedication in males $174(53 \%)$ than females $154(47 \%)$ which is in agreement with the findings of previous studies conducted in Portugal and Faisalabad. ${ }^{14,15}$ Specific to Indian society, males generally move freely outside their homes, are economically stronger and can easily access pharmacies. Possibly, more dependency of family members on males than females in our society may be a reason for the relatively low self-medication level seen in females.

The most common indication for self-medication among recruited subjects was fever, headache and weakness $(75.3 \%)$ followed by cough and cold $(51.5 \%)$. Other conditions were acidity, nausea and vomiting (30.5\%), diarrhea (17.98\%), skin diseases $(12.2 \%)$, pain abdomen $(9.8 \%)$, eye and ear problems $(7.9 \%)$, sleeplessness, anxiety, bad mood and tension $(6.1 \%)$. Of all recruited subjects $2.4 \%$ were taking drugs due to intense desire to take drug.

Similar to earlier observations in South India, current study also showed that most common reason for selfmedication among recruited subjects were "minor illness". Of public. ${ }^{16-19}$

Other reasons for self-medication include urgency, quick relief, cost effectiveness, confidence in self-diagnosis and pharmacological knowledge, previous expertise and old prescriptions. This observation is comparable to other studies. ${ }^{20}$

As stated earlier, analgesics, antibiotics and antipyretics were used by the majority of the students in our study for self-medication. This was Similar to finding observed by others.Family members and friends $(85.4 \%)$ and Pharmacist $(55.8 \%)$ were the main sources of drug information and procurement. ${ }^{21,22}$ The preferred route for administration of medicines was oral $(97.3 \%)$, injection (7.01\%), and inhalational (4.9\%).

Awareness about completing the course of antibiotics was present in $84.8 \%$ of subjects. However, $14.9 \%$ of the subjects were not completing the course of antibiotics during self-medication. Most of the subjects (87.8\%) checked expiry date of the drugs before use whereas, other $(12.2 \%)$ of subjects did not check the expiry date. All the subjects, irrespective of the year of the study reported that they were aware of the dosage, adverse drug reactions, expiry date and the importance of completing the course related to the self - medication drugs used by them.

In the present study $48.2 \%$ of the participants felt that selfmedication was part of self-care which was higher to that reported in studies from Ethiopia and Karachi. ${ }^{23}$ It was observed that $98(32.6 \%)$ students were in favor of selfmedication in future.

There are a few shortcomings of this study like recall bias, not revealing truth by the students and missing of some drugs used for self-medication. As this is a questionnaire based study, students were expected to complete the questionnaire independently but mutual influence between students could not be entirely ruled out.

\section{CONCLUSION}

Self-medicating practices are prevailing in the present generation of medical students of the institution where the current study was conducted. Regulations should be made to sensitize the health care students regarding the ills of such practice. The concerned agencies should frame certain policies such as continuous monitoring of dispensaries and drug stores to issue drugs only on authorized prescription. Possibly, health education and regulation of pharmacies may help in limiting the prevalent practices of selfmedication.

Funding: No funding sources

Conflict of interest: None declared

Ethical approval: The study was approved by the Institutional Ethics Committee

\section{REFERENCES}

1. Krishna J, Babu GC, Rajesh DR. An evaluation of self-medication among undergraduate medical students of a rural medical school from western Uttar Pradesh. IAIM. 2015;2(6):116-22.

2. World Health Organization. Role of the pharmacist in support of the WHO Revised Drug Strategy. World Health Assembly Resolution; 1994. 47.12.

3. Joint Statement by the International Pharmaceutical Federation and The World Self-Medication Industry. Responsible Self-Medication, 1998. Available at: http://www.fip.org/www/uploads/database_file.php?i $\mathrm{d}=241$ andtable_id.

4. Greenhalgh T. Drug prescription and self-medication in India: An exploratory survey. Soc Sci Med. 1987;25:307-18.

5. Deshpande SG, Tiwari R. Self-medication: A growing concern. Indian J Med Sci. 1997;51:93-6.

6. Hughes CM, McElnay JC, Fleming GF. Benefits and risks of self-medication. Drug Saf. 2001;24:1027-37.

7. World Health Organization. Regional Strategy on Prevention and Containment of Antimicrobial Resistance, 2010-2015. http://www.searo.who.int/entity/antimicrobial_resista nce/BCT_hlm-407.pdf.

8. Ganguly NK, Arora NK, Chandy SJ, Fairoze MN, Gill JP, Gupta U, et al. Global antibiotic resistance partnership (GARP): India Working Group. Rationalizing antibiotic use to limit antibiotic 
resistance in India. Indian J Med Res. 2011;134:28194.

9. Zafar SN, Reema S, Sana W, Akbar JZ, Talha V, Mahrine S, et al. Self medication amongst university students of Karachi: Prevalence, knowledge and attitudes. J Pak Med Assoc. 2008;58:214-17.

10. Banerjee I, Bhadury T. Self-medication practice among undergraduate medical students in a tertiary care medical college. West Bengal J Postgrad Med. 2012;58(2):127-31.

11. Sontakke SD, Bajait CS, Pimpalkhute SA, Jaiswal KM, Jaiswal SR. Comparative study of evaluation of self-medication practices in first and third year medical students. Int J Biol Med Res. 2011;2(2):56164.

12. Badiger S, Kundapur R, Jain A, Kumar A, Pattanshetty S, et al. Self-medication patterns among medical students in South India. Australas Med J. 2012;5(4):217-20.

13. Martins AP, Miranda Ada C, Mendes Z, Soares MA, Ferreira P, Nogueira A. Self-medication in a Portuguese urban population: a prevalence study. Pharmacoepidemiol. Drug Saf. 2002;11(5):409-14.

14. Baig S. Self medication practices. Prof Med J. 2012;19(4):513-21.

15. James H, Handu SS, Al Khaja KA, Otoom S, Sequeira RP. Evaluation of the knowledge, attitude and practice of self-medication among first-year medical students. Med Princ Pract. 2006; 15:270-5.

16. Sawalha AF. Assessment of self-medication practice among university students in palestine: Therapeutic and toxicity implications. Islam Univ J. 2007;15:6782.

17. Souza LA, da Silva CD, Ferraz GC, Sousa FA, Pereira LV. The prevalence and characterization of self- medication for obtaining pain relief among undergraduate nursing students. Rev Lat Am Enfermagem. 2011;19:245-51.

18. Nandha R, Chhabra MK. Prevalence and clinical characteristics of headache in dental students of tertiary care teaching dental hospital in Northern India. Int J Basic Clin Pharmacol. 2011;2:51-5.

19. Pandya RN, Jhaveri KS, Vyas FI, Patel VJ. Prevalence, pattern and perceptions of self-medication in medical students. Int $\mathrm{J}$ Basic Clin Pharmacol. 2013;2:275-80.

20. Patel PM, Prajapati AK, Ganguly B, Gajjar BM. Study on impact of Pharmacology teaching on knowledge, attitude and practice on self-medication among medical students. Int J Med Sci Pub Heal. 2013;2:1816.

21. Badiger S, Kundapur R, Jain A, Kumar A, Patanashetty S, Thakolkaran N, et al. Self-medication patterns among medical students in South India. Australas Med J. 2012;5:217-20.

22. Abay SM, Amelo W. Assessment of self-medication practices among medical, pharmacy, and health science students in Gondar University, Ethiopia. J Young Pharm. 2010;2:306-10.

23. Hooper C, Meakin R, Jones M. Where students go when they are ill: How medical students access health care. Med Educ. 2005;39:588-93.

Cite this article as: Singh $\mathrm{S}$, Singh R, Singh V, Gupta B. Practice of self-medication among medical students in a region of northern state of India. Int $\mathrm{J}$ Basic Clin Pharmacol 2019;8:488-92. 